\title{
Preferable Effect of Pravastatin Compared to Atorvastatin on Beta Cell Function in Japanese Early-state Type 2 Diabetes with Hypercholesterolemia
}

\author{
TOMOYA MITA, HiRotaka WATADA, SHIHO NAKAYAMA, MichiKo ABE, TAKESHI OGIHARA, \\ TOMOAKI SHIMIZU, HIROSHI UCHINO, TAKAHISA HIROSE AND RYUZO KAWAMORI
}

Department of Medicine, Metabolism and Endocrinology, Juntendo University School of Medicine, 2-1-1 Hongo, Bunkyo-ku, Tokyo 113-8421, Japan

\begin{abstract}
While a large numbers of clinical trials using various kinds of statins has been reported, a possible preventive effect on new onset of type 2 diabetes mellitus was shown only by the subanalysis of The West of Scotland Coronary Prevention Study (WOSCOPS) using pravastatin. The aim of this study was to investigate whether pravastatin has a preferable effect on glucose tolerance among statins. An open-label prospective cross-over trial was performed to compare the effect of pravastatin $(10 \mathrm{mg} /$ day $)$ or atorvastatin $(10 \mathrm{mg} /$ day $)$ in Japanese early-state type 2 diabetes mellitus with hypercholesterolemia. The analyzed study subjects were treated with pravastatin $(10 \mathrm{mg} / \mathrm{day}, \mathrm{n}=12)$ or atorvastatin $(10 \mathrm{mg} /$ day, $\mathrm{n}=12)$ for 12 weeks. After a 4-week-washout period, the drugs were switched and treatment was continued for another 12 weeks. Oral glucose tolerance test (OGTT) was performed to evaluate several parameters including the appropriateness of beta cell function for the individual insulin sensitivity (disposition index: product of a validated secretion parameter and sensitivity) at the end of each therapy. $\mathrm{HbA}_{1 \mathrm{c}}$ and $2 \mathrm{~h}$-glucose levels during OGTT in the pravastatin treatment were significantly lower than atorvastatin treatment. Disposition index after pravastatin treatment was significantly higher than after atorvastatin treatment. In conclusion, our study suggests that pravastatin has a favorable effect on pancreatic beta cell function compared with atorvastatin.
\end{abstract}

Key words: 3-Hydroxy-3-methylglutaryl coenzyme A reductase inhibitor, Type 2 diabetes mellitus, Pancreatic beta cell, Hyperlipidemia, Clinical trial

(Endocrine Journal 54: 441-447, 2007)

PATIENTS with type 2 diabetes have a high risk of developing cardiovascular disease which is also the most frequent cause of death in these patients [1]. Especially, type 2 diabetes complicated with hyperlipidemia has an elevated risk of developing atherosclerosis. The lipid profile of these patients are characterized by both quantitative and qualitative changes in lipoproteins, such as increased triglyceride-rich remnants, low HDL cholesterol, increased small dense LDL choles-

Received: November 16, 2006

Accepted: February 2, 2007

Correspondence to: Hirotaka WATADA, M.D., Department of Medicine, Metabolism and Endocrinology, Juntendo University School of Medicine, 2-1-1 Hongo, Bunkyo-ku, Tokyo 113-8421, Japan terol and modest increase in LDL cholesterol [2]. According to the results of the United Kingdom Prospective Diabetes Study (UKPDS), LDL cholesterol is the most important determinant for the development of cardiovascular disease in type 2 diabetes mellitus [3]. Several large clinical trials demonstrated that 3hydroxy-3-methylglutaryl coenzyme A reductase inhibitor, known as statins, which reduces LDL cholesterol results in substantial benefits for diabetic patients with hypercholesterolemia [4-7].

Beyond the effect of reducing serum cholesterol, statins have other beneficial effects such as reduced expression of adhesion molecules, inhibition of the proliferation and migration of vascular smooth muscle cell $[8,9]$, anti-thrombotic effects [10], and reduction of inflammation [11], which have been known as their 
pleiotropic effects. All statins commonly share such effects. However, regarding the effects of statins on the prevention of the development of new type 2 diabetes mellitus in clinical setting, only the substudy of The West of Scotland Coronary Prevention Study (WOSCOPS) using pravastatin is available [12]. Despite the presence of huge data using other types of statins, no studies dealing with large study subjects have shown such effects. Thus, it is possible that pravastatin might have more favorable pleiotropic effects on glucose tolerance than other statins. Even if statins had such effects, it is predicted that they should be very mild. Thus, to elucidate the effect of pravastatin on glucose metabolism, we should use sensitive parameters to evaluate pancreatic beta cell function, insulin sensitivity and glucose tolerance.

It has been previously reported that the relationship between insulin secretion and insulin sensitivity is curvilinear. Thus, the disposition index, the product of a validated secretion parameter and sensitivity is constant if the beta cell function is not affected. Due to this relationship, insulin resistance is compensated by the increase in insulin secretion [13]. In contrast, the increased insulin sensitivity observed such as after weight reduction is accompanied by the reduced insulin secretion in obese subjects [14]. It has been estimated that this adjustment of insulin secretion might be achieved by the changes of beta cell mass, and/or glucose sensitivity for insulin secretion [15]. Impaired glucose tolerance or type 2 diabetes develops and progresses if the compensation of insulin secretion in islet is inadequate to insulin resistance, which is represented by the decrease in disposition index $[13,16,17]$.

The primary aim of the present study is to validate the effect of pravastatin on beta cell function. Because the residual beta cell capacity in type 2 diabetes is variable among the subjects, we chose a crossover design to allow treatment comparisons in one subject rather than between subjects. To assess beta cell function, the effect of each treatment was primarily evaluated by disposition index in all study subjects. In addition, to evaluate the data obtained by oral glucose tolerance test (OGTT) properly, we chose early-state type 2 diabetes as the study subjects.

\section{Materials and Methods}

\section{Subjects}

The patients with type 2 diabetes mellitus who visited Juntendo University Hospital (Tokyo, Japan) or Secomedic Hospital (Funabashi, Japan) from April 2005 to August 2005 were asked to participate in the study. The inclusion criteria of this study were type 2 diabetes mellitus with hypercholesterolemia who receive pravastatin $10 \mathrm{mg}$ or atorvastatin $10 \mathrm{mg}$ and their $\mathrm{HbA}_{1 \mathrm{c}}$ level was less than $6.5 \%$ at the inclusion of this study. The diagnosis of type 2 diabetes was based on the current WHO criteria. The patients with diabetic microangiopathy, severe renal or hepatic disease, overt cardiovascular disease, and malignancy were excluded. Also the patients receiving insulin or sulfonylurea were excluded. The patients taking other oral hypoglycemic drugs were enrolled and the dosage of the drugs was not changed during this study. A total of 25 Japanese subjects were recruited for this study. The hospital ethics committee approved this study protocol and informed consent was obtained from each subject.

\section{Study design}

An open-label, crossover design was used. After screening visit, 12 subjects receiving pravastatin $(10 \mathrm{mg} /$ day $)$ and 13 subjects receiving atorvastatin $(10 \mathrm{mg} /$ day $)$ were recruited. Except one case of drop out, each patient continued to take the respective drug for 12 weeks. Then, oral glucose tolerance test was performed and simultaneously, fasting blood sample was collected to measure other parameters. Then, each drug was stopped for 4 weeks and at the end of washout period, fasting blood samples were collected. Subsequently, the subjects on pravastatin switched to atorvastatin and the subjects on atorvastatin switched to pravastatin for 12 weeks, after which another OGTT was performed with fasting blood sampling to measure other parameters. All subjects were recommended to consume their habitual diet during the study period. Each patient was reviewed as to their general health and compliance with medications as assessed by tablets counts with laboratory data, blood pressure, body weight and diet and exercise status being checked at each visit. The clinical characteristics of the patients are shown in Table 1. 
Table 1. Baseline Characteristics of Study Subjects

\begin{tabular}{lc}
\hline & $(\mathrm{n}=24)$ \\
\hline Age & $62.0 \pm 8.5$ \\
Gender $($ Female $/$ male $)$ & $10 / 14$ \\
BMI $\left(\mathrm{kg} / \mathrm{m}^{2}\right)$ & $24.4 \pm 2.6$ \\
Waist $(\mathrm{cm})$ & $85.5 \pm 8.3$ \\
Estimated diabetic duration (years) & $3.4 \pm 2.2$ \\
Current smoking (yes/no) & $5 / 19$ \\
Presence of MS (yes/no) & $15 / 9$ \\
Treatment of diabetes & \\
$\quad \alpha-G I$ & $1 / 24$ \\
$\quad$ Nateglinide & $2 / 24$ \\
$\quad$ Metformin & $1 / 24$ \\
Diet only & $20 / 24$ \\
Antihypertensive therapy & \\
CCBs & $7 / 24$ \\
$\quad$ ARBs & $8 / 24$ \\
Others & $0 / 24$ \\
Fibrate & $0 / 24$ \\
Antithrombotics & $0 / 24$ \\
\hline
\end{tabular}

Data represent the mean value \pm S.D. or number of subjects. Abbreviations: BMI, body mass index; MS, metabolic syndrome; $\alpha$-GI, $\alpha$-glucosidase inhibitors; CCB, calcium channel blockers; $\mathrm{ARB}$, angiotensin receptor blockers.

\section{Definitions}

Hypertension was defined by casual blood pressure $\geq 140 / 90 \mathrm{mmHg}$. Dyslipidemia was defined by fasting serum total cholesterol $>220 \mathrm{mg} / \mathrm{dl}, \mathrm{TG} \geq 150 \mathrm{mg} / \mathrm{dl}$, HDL cholesterol $<40 \mathrm{mg} / \mathrm{dl}$ or LDL cholesterol $>140$ $\mathrm{mg} / \mathrm{dl}$. Diagnosis of metabolic syndrome was defined as the presence of central obesity (waist circumference $>90 \mathrm{~cm}$ for women, $>85 \mathrm{~cm}$ for men. These criteria are only applicable to Japanese) plus following two components: 1) triglycerides $\geq 150 \mathrm{mg} / \mathrm{dl}$, or HDL cholesterol $<50 \mathrm{mg} / \mathrm{dl}$ for women and $<40 \mathrm{mg} / \mathrm{dl}$ for men, 2) systolic blood pressure $\geq 130 \mathrm{mmHg}$ or diastolic blood pressure $\geq 85 \mathrm{mmHg}, 3$ ) fasting blood sugar $\geq 110 \mathrm{mg}$ / dl.

\section{Biochemical measurements}

Blood samples were obtained between 8 and 10 A.M. after overnight fast for the measurement of serum lipids (total cholesterol, HDL cholesterol, LDL cholesterol and triglycerides) and glucose by standard laboratory techniques. Safety parameters included creatinine, alanine aminotransferase (AST), aspartate aminotransferase (ALT), and creatine phosphokinase
(CPK) were measured with standard techniques. Plasma insulin concentrations, highly sensitive C-reactive protein (hs-CRP), leptin and adiponectin were analyzed by a private laboratory using ELISA (SRL Laboratory, Tokyo, Japan).

\section{OGTT}

A standard 2 hour $75 \mathrm{~g}$ OGTT was performed at 9:00 h after $12 \mathrm{~h}$ overnight fast. Blood samples were collected at $0,30,60,90$ and $120 \mathrm{~min}$ for the measurement of plasma glucose and insulin.

\section{Calculations}

To assess beta cell function, we used the insulinogenic index (IGI) which is calculated as the increment in the serum insulin level $(\mu \mathrm{U} / \mathrm{ml})$ in 30 min divided by the corresponding increment of serum glucose $(\mathrm{mg} / \mathrm{dl})$ [18-20]. Insulin resistance was determined by two methods; homeostasis model assessment of insulin resistance (HOMA-IR) calculated as the product of the fasting plasma insulin $(\mu \mathrm{U} / \mathrm{ml})$ and the fasting plasma glucose level (mg/dl) divided by 405 and the composite whole-body-insulin-sensitivity index (WBISI) calculated using mean values of insulin $(\mu \mathrm{U} / \mathrm{ml})$ and glucose $(\mathrm{mg} / \mathrm{dl})$ obtained from the OGTT and corresponding fasting values [21]. The appropriateness of beta cell function for the individual insulin sensitivity was evaluated by the disposition index, calculated as the product of IGI and WBISI [22-24].

\section{Statistical analysis}

Results are presented as the mean $\pm \mathrm{SD}$. Statistical analysis to compare the variables of each group was performed using two group $t$ tests. Statistical significance was defined at $\mathrm{P}<0.05$.

\section{Results}

One patient dropped out of this study due to having muscle pain with atorvastatin although laboratory examination did not reveal any significant findings. Thus, in the present study, we analyzed the data of 24 patients. Regarding the treatment of diabetes, most patients (20/24) were treated without any oral hypoglycemic agents. The presence of metabolic syndrome 
Table 2. Biochemical Characteristics in Each Treatment Group

\begin{tabular}{|c|c|c|c|c|}
\hline & Pravastatin & Atorvastatin & $P$ value & Washout Period \\
\hline BMI & $24.4 \pm 2.6$ & $24.4 \pm 2.7$ & 0.93 & $24.4 \pm 2.7$ \\
\hline $\mathrm{TC}(\mathrm{mg} / \mathrm{dl})$ & $201.5 \pm 23.5$ & $175.5 \pm 25.5$ & $\leq 0.001$ & $243.0 \pm 21.3$ \\
\hline $\mathrm{HDL}-\mathrm{C}(\mathrm{mg} / \mathrm{dl})$ & $59.1 \pm 13.1$ & $59.1 \pm 13.4$ & 0.98 & $57.6 \pm 14.3$ \\
\hline LDL-C(mg/dl) & $117.9 \pm 17.7$ & $90.6 \pm 19.0$ & $\leq 0.001$ & $146.3 \pm 24.9$ \\
\hline TG (mg/dl) & $128.3 \pm 64.3$ & $117.8 \pm 87.2$ & 0.50 & $143.0 \pm 70.4$ \\
\hline sBP (mmHg) & $136.8 \pm 12.0$ & $137.1 \pm 13.3$ & 0.81 & $134.5 \pm 13.3$ \\
\hline $\mathrm{dBP}(\mathrm{mmHg})$ & $80.3 \pm 12.7$ & $80.2 \pm 13.2$ & 0.97 & $78.7 \pm 13.0$ \\
\hline hs CRP (mg/l) & $0.61 \pm 0.47$ & $0.67 \pm 0.71$ & 0.35 & $0.91 \pm 0.95$ \\
\hline Adiponectin $(\mu \mathrm{g} / \mathrm{ml})$ & $8.4 \pm 3.0$ & $8.6 \pm 3.1$ & 0.60 & $8.4 \pm 3.2$ \\
\hline Leptin (ng/ml) & $7.2 \pm 6.3$ & $7.2 \pm 6.1$ & 0.41 & $7.4 \pm 6.0$ \\
\hline $\mathrm{HbA}_{1 \mathrm{c}}(\%)$ & $5.80 \pm 0.52$ & $5.97 \pm 0.58$ & $\underline{0.003}$ & $5.84 \pm 0.55$ \\
\hline Glucose (mg/dl) & $116.9 \pm 21.5$ & $121.2 \pm 18.1$ & 0.132 & $117.8 \pm 15.6$ \\
\hline Glucose $120 \mathrm{~min}(\mathrm{mg} / \mathrm{dl})$ & $216.1 \pm 73.0$ & $230.9 \pm 77.2$ & $\underline{0.049}$ & ND \\
\hline Insulin $(\mu \mathrm{U} / \mathrm{ml})$ & $7.84 \pm 4.86$ & $7.93 \pm 3.58$ & 0.132 & $8.09 \pm 4.38$ \\
\hline Insulin $120 \mathrm{~min}(\mu \mathrm{U} / \mathrm{ml})$ & $60.4 \pm 37.9$ & $63.4 \pm 36.4$ & 0.08 & ND \\
\hline $\mathrm{AUC}_{\text {glucose }}$ & $24136 \pm 5490$ & $25144 \pm 5291$ & 0.07 & ND \\
\hline $\mathrm{AUC}_{\text {insulin }}$ & $4972.1 \pm 2528.4$ & $5165.5 \pm 2792.1$ & 0.65 & ND \\
\hline HOMA-IR & $2.25 \pm 1.46$ & $2.35 \pm 1.08$ & 0.39 & $2.31 \pm 1.21$ \\
\hline WBISI & $5.65 \pm 5.35$ & $4.25 \pm 2.10$ & 0.10 & ND \\
\hline IGI & $0.32 \pm 0.19$ & $0.28 \pm 0.20$ & 0.12 & ND \\
\hline Disposition index & $1.36 \pm 0.79$ & $1.00 \pm 0.60$ & $\underline{0.002}$ & ND \\
\hline
\end{tabular}

Data are expressed as means \pm SD. Statistical analysis was performed to compare the variables of pravastatin group and atorvastatin group using two group $t$ tests. P values which is considered to be statistically significant was shown by underline. Abbreviations: BMI, body mass index; TC, total cholesterol; HDL-C, HDL cholesterol; LDL-C, LDL cholesterol; TG, triglyceride; sBP, systolic blood pressure; $\mathrm{dBP}$, diastolic blood pressure; hs-CRP, highly sensitive C-reactive protein; $\mathrm{AUC}_{\text {glucose }}$, area under the curve of glucose level during oral glucose tolerance test; $\mathrm{AUC}_{\text {insulin, }}$, area under the curve of glucose level during oral glucose tolerance test; HOMA-IR, homeostasis model assessment of insulin resistance; WBISI, whole-body-insulin-sensitivity index; IGI, insulinogenic index.

was $62.5 \%$ at baseline (Table 1). During the study period, no patients showed more than 1.5 fold changes of creatinine, AST, ALT or CPK level.

The reductions of total cholesterol and LDLcholesterol in the atorvastatin group were significantly greater than the pravastatin group. On the other hand, plasma HDL-cholesterol and triglyceride level were not different between each treatment. Hs-CRP was decreased by the treatment with either of the statins, however, it was not different between each treatment. Adiponectin and leptin level was not affected by each treatment.

Interestingly, disposition index, a marker of $\beta$ cell function was significantly higher with the treatment of pravastatin compared to atorvastatin (Table 2). Reflecting this difference, $\mathrm{HbA}_{\mathrm{lc}}$ and $2 \mathrm{~h}$-glucose levels were significantly lower with pravastatin compared to atorvastatin. The area under the curve of glucose level during OGTT, WBISI, and IGI in the pravastatin treatment tended to be lower than the atorvastatin treatment, though these differences were not statistically significant.

\section{Discussion}

The aim of this study is to elucidate the effect of pravastatin on glucose tolerance and its related parameters compared with atorvastatin. In the present study, pravastatin significantly reduced $\mathrm{HbA}_{1 \mathrm{c}}$ and $2 \mathrm{~h}$ glucose levels compared with atorvastatin in agreement with recent studies $[25,26]$. This amelioration of blood glucose level and glucose tolerance was concurrent with the significant improvement of disposition index, an index that represents the appropriateness of beta cell function for the individual insulin sensitivity.

In this study, the differences of disposition index between the treatment of pravastatin and atorvastatin observed in our data was $36.0 \%$. While accumulated data have demonstrated that thiazolidinediones have prefer- 
able effects on $\beta$ cell preservation [27, 28], recent data reported that the treatment with rosiglitazone for 6 months improves disposition index of type 2 diabetes by $43 \%$ [29]. Whereas caution should be taken in view of the differences in the study condition, the improvement of disposition index by pravastatin, compared with atorvastatin should not be regarded as negligible. Our data indicate that pravastatin has more favorable effect on beta cell function than atorvastatin.

Statins modestly reduce serum triglyceride level and have systemic anti-inflammatory effect. These effects might be related to the improvement of beta cell function. However, in the present study, serum triglyceride and hs-CRP, the marker of systemic inflammation level, were not different between the treatment of pravastatin and atorvastatin. Furthermore, although a very recent study revealed that pravastatin modestly increases serum adiponectin level [30], the treatment with either of the statins did not affect the plasma adiponectin and leptin concentrations in our study subjects. Thus, the mechanism of the preferable effect of pravastatin seems to be independent of such markers and should be elucidated.

Recently, possible unfavorable effects of some lipophilic statins on glucose metabolism have been reported. Lipophilic statins such as lovastatin, atorvastatin, simvastatin, and cerivastatin may be incorporated into various organs such as pancreas, adipose tissue and muscle which are important for glucose metabolism, while hydrophilic statins such as pravastatin is incorporated mainly into liver. The characteristic difference might result in a different action on glucose tolerance. For instance, as lovastatin inhibited insulin secretion from isolated islets [31], simvastatin inhibited insulin secretion via the blockage of L-type calcium channels in rat pancreatic beta cell, while pravastatin did not [32]. While pravastatin prevented the deterioration of glucose tolerance in OLETF rats, a recent study reported that atorvastatin impaired glucose tolerance in NSY mice [33]. On the other hand, there have been several data disputing these results $[34,35]$. Regarding the present study, we performed OGTT in 7 subjects just before the administration of statins. As a result, pravastatin tended to improve beta cell function, while atorvastatin does not affect beta cell function (disposition index before the treatment, $0.96 \pm 0.32$; during the treatment of pravastatin, $1.51 \pm 0.77$; during the treatment of atorvastatin, $1.04 \pm 0.32$ ). Thus, our data supported the view that pravastatin has a favorable effect on beta cells, rather than the view that atorvastatin has an unfavorable effect.

Our data indicates that pravastatin has beneficial effects on $\beta$ cell function, compared with atorvastatin. However, in order to prevent cardiovascular diseases, the reduction of LDL cholesterol level is critical. To achieve the target LDL cholesterol level, we should not hesitate to use atorvastatin even for patients with type 2 diabetes, because the effect on $\beta$ cell function seems to be modest in clinical setting.

In conclusion, our study demonstrated the beneficial effects of pravastatin on beta cell function compared with atorvastatin in early-state type 2 diabetic patients with hypercholesterolemia. Also, our study clearly provides useful information for drug choice in clinical setting. In addition, our data support the necessity of further study to elucidate the mechanism to the unique effect of pravastatin. This knowledge would eventually be used to make compounds to improve beta cell function.

\section{References}

1. Ruderman NB, Haudenschild C (1984) Diabetes as an atherogenic factor. Prog Cardiovasc Dis 26: 373-412.

2. Izkhakov E, Meltzer E, Rubinstein A (2003) Pathogenesis and management of diabetic dyslipidemia. Treat Endocrinol 2: 231-245.

3. Turner RC, Millns H, Neil HA, Stratton IM, Manley SE, Matthews DR, Holman RR (1998) Risk factors for coronary artery disease in non-insulin dependent diabetes mellitus: United Kingdom Prospective Diabetes Study (UKPDS: 23). Bmj 316: 823-828.

4. (1994) Randomised trial of cholesterol lowering in
4444 patients with coronary heart disease: the Scandinavian Simvastatin Survival Study (4S). Lancet 344: 1383-1389.

5. Shepherd J, Cobbe SM, Ford I, Isles CG, Lorimer AR, MacFarlane PW, McKillop JH, Packard CJ (1995) Prevention of coronary heart disease with pravastatin in men with hypercholesterolemia. West of Scotland Coronary Prevention Study Group. $N$ Engl J Med 333: 1301-1307.

6. Sacks FM, Pfeffer MA, Moye LA, Rouleau JL, Rutherford JD, Cole TG, Brown L, Warnica JW, 
Arnold JM, Wun CC, Davis BR, Braunwald E (1996) The effect of pravastatin on coronary events after myocardial infarction in patients with average cholesterol levels. Cholesterol and Recurrent Events Trial investigators. N Engl J Med 335: 1001-1009.

7. Colhoun HM, Betteridge DJ, Durrington PN, Hitman GA, Neil HA, Livingstone SJ, Thomason MJ, Mackness MI, Charlton-Menys V, Fuller JH (2004) Primary prevention of cardiovascular disease with atorvastatin in type 2 diabetes in the Collaborative Atorvastatin Diabetes Study (CARDS): multicentre randomised placebo-controlled trial. Lancet 364: 685-696.

8. Corsini A, Mazzotti M, Raiteri M, Soma MR, Gabbiani G, Fumagalli R, Paoletti R (1993) Relationship between mevalonate pathway and arterial myocyte proliferation: in vitro studies with inhibitors of HMG-CoA reductase. Atherosclerosis 101: 117-125.

9. Yamakawa T, Tanaka S, Kamei J, Kadonosono K, Okuda K (2003) Pitavastatin inhibits vascular smooth muscle cell proliferation by inactivating extracellular signal-regulated kinases 1/2. J Atheroscler Thromb 10: 37-42.

10. Kearney D, Fitzgerald D (1999) The anti-thrombotic effects of statins. J Am Coll Cardiol 33: 1305-1307.

11. Marz W, Wieland H (2000) HMG-CoA reductase inhibition: anti-inflammatory effects beyond lipid lowering? Herz 25: 117-125.

12. Freeman DJ, Norrie J, Sattar N, Neely RD, Cobbe SM, Ford I, Isles CC, Lorimer AR, Macfarlane PW, McKillop JH, Packard CJ, Shepherd J, Gaw A (2001) Pravastatin and the development of diabetes mellitus: evidence for a protective treatment effect in the West of Scotland Coronary Prevention Study. Circulation 103: 357-362.

13. Bergman RN, Ader M, Huecking K, Van Citters G (2002) Accurate assessment of beta-cell function: the hyperbolic correction. Diabetes 51 (Suppl 1): S212220.

14. Guldstrand M, Ahren B, Adamson U (2003) Improved beta-cell function after standardized weight reduction in severely obese subjects. Am J Physiol Endocrinol Metab 284: E557-565.

15. Weir GC, Laybutt DR, Kaneto H, Bonner-Weir S, Sharma A (2001) Beta-cell adaptation and decompensation during the progression of diabetes. Diabetes 50 (Suppl 1): S154-159.

16. Kahn SE (2001) Clinical review 135: The importance of beta-cell failure in the development and progression of type 2 diabetes. J Clin Endocrinol Metab 86: 40474058.

17. Weyer C, Bogardus C, Mott DM, Pratley RE (1999) The natural history of insulin secretory dysfunction and insulin resistance in the pathogenesis of type 2 diabetes mellitus. J Clin Invest 104: 787-794.

18. Ichikawa K, Akanuma Y, Kosaka K, Kuzuya N (1977)
The effect of obesity on plasma triglycerides and fasting plasma IRI levels. Significance of insulinogenic index and glucose tolerance. Horm Metab Res 9: 429430 .

19. Kosaka K, Kuzuya T, Yoshinaga H, Hagura R (1996) A prospective study of health check examinees for the development of non-insulin-dependent diabetes mellitus: relationship of the incidence of diabetes with the initial insulinogenic index and degree of obesity. Diabet Med 13: S120-126.

20. Stumvoll M, Mitrakou A, Pimenta W, Jenssen T, YkiJarvinen H, Van Haeften T, Renn W, Gerich J (2000) Use of the oral glucose tolerance test to assess insulin release and insulin sensitivity. Diabetes Care 23: 295301.

21. Matsuda M, DeFronzo RA (1999) Insulin sensitivity indices obtained from oral glucose tolerance testing: comparison with the euglycemic insulin clamp. Diabetes Care 22: 1462-1470.

22. Weiss R, Taksali SE, Tamborlane WV, Burgert TS, Savoye M, Caprio S (2005) Predictors of changes in glucose tolerance status in obese youth. Diabetes Care 28: 902-909.

23. Thamer C, Stumvoll M, Niess A, Tschritter O, Haap M, Becker R, Shirkavand F, Bachmann O, Rett K, Volk A, Haring H, Fritsche A (2003) Reduced skeletal muscle oxygen uptake and reduced beta-cell function: two early abnormalities in normal glucose-tolerant offspring of patients with type 2 diabetes. Diabetes Care 26: 2126-2132.

24. Yeckel CW, Taksali SE, Dziura J, Weiss R, Burgert TS, Sherwin RS, Tamborlane WV, Caprio S (2005) The normal glucose tolerance continuum in obese youth: evidence for impairment in beta-cell function independent of insulin resistance. $J$ Clin Endocrinol Metab 90: 747-754.

25. Ishikawa M, Namiki A, Kubota T, Yajima S, Fukazawa M, Moroi M, Sugi K (2006) Effect of pravastatin and atorvastatin on glucose metabolism in nondiabetic patients with hypercholesterolemia. Intern Med 45: 51-55.

26. Takano T, Yamakawa T, Takahashi M, Kimura M, Okamura A (2006) Influences of statins on glucose tolerance in patients with type 2 diabetes mellitus. $J$ Atheroscler Thromb 13: 95-100.

27. Xiang AH, Peters RK, Kjos SL, Marroquin A, Goico J, Ochoa C, Kawakubo M, Buchanan TA (2006) Effect of pioglitazone on pancreatic beta-cell function and diabetes risk in Hispanic women with prior gestational diabetes. Diabetes 55: 517-522.

28. Buchanan TA, Xiang AH, Peters RK, Kjos SL, Marroquin A, Goico J, Ochoa C, Tan S, Berkowitz K, Hodis HN, Azen SP (2002) Preservation of pancreatic beta-cell function and prevention of type 2 diabetes by pharmacological treatment of insulin resistance in high-risk Hispanic women. Diabetes 51: 2796-2803. 
29. Ovalle F, Bell DS (2004) Effect of rosiglitazone versus insulin on the pancreatic beta-cell function of subjects with type 2 diabetes. Diabetes Care 27: 2585-2589.

30. Sakamoto K, Sakamoto T, Ogawa H, Investigators ftKJRoHK (2006) The effect of 6 months of treatment with pravastatin on serum adiponectin concentration in Japanese patients with coronary artery disease and hypercholesterolemia: A pilot study. Clin Ther 28: 10121021.

31. Metz SA, Rabaglia ME, Stock JB, Kowluru A (1993) Modulation of insulin secretion from normal rat islets by inhibitors of the post-translational modifications of GTP-binding proteins. Biochem J 295 ( Pt 1): 31-40.

32. Yada T, Nakata M, Shiraishi T, Kakei M (1999) Inhibition by simvastatin, but not pravastatin, of glucoseinduced cytosolic $\mathrm{Ca} 2+$ signalling and insulin secretion due to blockade of L-type $\mathrm{Ca} 2+$ channels in rat islet beta-cells. Br J Pharmacol 126: 1205-1213.

33. Nakata M, Nagasaka S, Kusaka I, Matsuoka H, Ishibashi S, Yada T (2006) Effects of statins on the adipocyte maturation and expression of glucose transporter 4 (SLC2A4): implications in glycaemic control. Diabetologia 49: 1881-1892.

34. Paniagua JA, Lopez-Miranda J, Escribano A, Berral FJ, Marin C, Bravo D, Paz-Rojas E, Gomez P, Barcos M, Moreno JA, Perez-Jimenez F (2002) Cerivastatin improves insulin sensitivity and insulin secretion in earlystate obese type 2 diabetes. Diabetes 51: 2596-2603.

35. Suzuki M, Kakuta H, Takahashi A, Shimano H, TadaIida K, Yokoo T, Kihara R, Yamada N (2005) Effects of atorvastatin on glucose metabolism and insulin resistance in KK/Ay mice. J Atheroscler Thromb 12: $77-$ 84. 